\title{
Assessment of hypertensive patients self-care agency after counseling training of nurses
}

\author{
Eva Drevenhorn, Ann Bengtson, Per Nyberg and Karin Kjellgren
}

\section{Linköping University Post Print}

\section{Tweet}

N.B.: When citing this work, cite the original article.

Original Publication:

Eva Drevenhorn, Ann Bengtson, Per Nyberg and Karin Kjellgren, Assessment of hypertensive patients self-care agency after counseling training of nurses, 2015, Journal of the American Association of Nurse Practitioners, (27), 11, 624-630.

http://dx.doi.org/10.1002/2327-6924.12222

Copyright: Wiley

http://eu.wiley.com/WileyCDA/

Postprint available at: Linköping University Electronic Press

http://urn.kb.se/resolve?urn=urn:nbn:se:liu:diva-123068 


\title{
Assessment of hypertensive patients' self-care agency after counseling training of nurses
}

Eva Drevenhorn, RN, $\mathrm{PhD}^{\mathrm{a}}$, Ann Bengtson, RNT, $\mathrm{PhD}^{\mathrm{b}}$, Per Nyberg, $\mathrm{PhD}^{\mathrm{a}}$, Karin I Kjellgren, $\mathrm{RN}, \mathrm{PhD}^{\mathrm{b}, \mathrm{c}}$

${ }^{a}$ Department of Health Sciences, Faculty of Medicine, Lund University, Box 117, SE-221 00 Lund, Sweden

${ }^{\mathrm{b}}$ Institute of Health and Care Sciences, The Sahlgrenska Academy, University of Gothenburg, Box 457, SE-405 30 Gothenburg, Sweden

c Department of Medical and Health Sciences, Linköping University, SE-581 85 Linköping, Sweden

Corresponding author

Eva Drevenhorn, Department of Health Sciences, Faculty of Medicine, Lund University

Box 117, SE-221 00 Lund, Sweden, eva.drevenhorn@med.lu.se, Tel: +46 +46222 1928

Published first online Febr 2015 in Journal of the American Association of Nurse

Practitioners, doi: 10.1002/2327-6924.12222

\begin{abstract}
Purpose: The aim of the study was to assess hypertensive patients' self-care agency and any correlation with the patient's lifestyle changes and the nurse's degree of patient-centeredness after counseling training.

Data sources: Nurses in the intervention group (IG) $(n=19)$ working at nurse-led clinics at health centers were trained in patient-centeredness (Motivational Interviewing (MI)) and the Stages of Change (SOC) model and included 137 patients. Nurses in the control group (CG) $(n=14)$ included 51 patients. The Exercise of Self-Care Agency (ESCA) instrument was used. There was a significant difference from baseline to the two-year follow-up in the ESCA score (IG p=0.0001). An increase in ESCA score was correlated with an increased level of physical activity after two years (IG p=0.0001; CG $\mathrm{p}=0.040$ ).

Conclusions: The counseling training gave an increase in the patients' self-care agency scores, which was significantly correlated with increased physical activity.

Implications for practice: In clinical practice it is important for nurses to be patient centered in their counseling to affect patients' self-care agency in a positive direction.
\end{abstract}

\section{Keywords}

counseling, hypertension, self care, patient-centered care 


\section{Introduction}

To counsel patients with hypertension to improve their lifestyle regarding diet, physical activity, use of tobacco, alcohol consumption and stress is a key task for nurses (Bengtson \& Drevenhorn, 2003). A change of lifestyle implies that the patient performs self-care (Pender, 1996). Patients' preferences affect the self-care they do or do not perform when it comes to changing lifestyle, as they have ideas about what health means, as well as ideas about how to judge whether they are healthy or unhealthy (Jallinoja et al., 2008). This is exemplified in Dorothea Orem's nursing theory of self-care deficit (Orem, 2001). Presuppositions for the theory are that people develop and perform intellectual and practical skills through learning and can thereby manage to maintain their own motivation for continuing daily care. In this context that could be to start exercising to lower one's elevated blood pressure. Whether the patient performs lifestyle changes or not varies depending on capabilities and circumstances of the individual patient's power of self-care agency. Self-care deficit means that capabilities for self-care do not meet some or all of a person's self-care demands due to e.g. a lack of understanding of the importance of lifestyle changes or having other values in life. This is confirmed in interviews with hypertensive patients by Whetstone and Reid (1991), who found barriers to perform self-care such as diet and weight problems, medication taking, fear associated with stroke potential and lack of support; all indicators of self-care deficits.

The theory of nursing systems is the important organizing part which subsumes the theory of self-care deficit and theory of self-care. The nursing system is made up of the selected and performed actions of nurses (nursing agencies) and may be of long or short duration for persons who have health-related deficits. The aim of nursing in the theory is helping patients to attain self-care, which also is the aim of counselling about lifestyle changes in hypertension care. Specifically in hypertension care, nursing is supportive-educative with the goal of helping the patients to regain their self-care. The supportive-educative system requires teaching and supporting the patients in decision-making, and management in order to achieve a healthy lifestyle. Some research has used this approach in different contexts regarding medication for congestive heart failure after discharge from hospital (Fujita \& Dungan, 1994); the work of nurse practitioners in primary care settings (Geden et al., 2001) and the categorization of the barriers that patients with heart failure experience in self-care behavior (Jaarsma et al., 2000) but has not been found to be used in hypertension care before. When using this supportive-educative system for nursing actions, a greater effect is seen in patients' lifestyle changes when nurses are patient-centered in their counseling (Britt et al., 2004), and this is the aim of the Motivational Interviewing (MI) used in our intervention (Rollnick et al., 2002). In the research project, Nursing Management of Patients in Hypertension Care, we wished to evaluate the effects of the counseling training of nurses in hypertension care on hypertensive patients' self-care agency in an intervention group (IG) and a control group (CG). The association between self-care agency score and implemented lifestyle changes (IG and CG) and degree of patient-centeredness (IG) in the counseling was also studied.

\section{Materials and Methods}

In our randomized pretest-posttest study, two groups of randomized nurses with their consecutively included patients were compared. The nurses were recruited from a register of 
all the nurses who were members of the Swedish Hypertension Society and from a register of all nurse-led hypertension clinics at health centers in Sweden (Figure 1). The nurses were asked to participate and were then randomly allocated to IG $(n=19)$ or CG $(n=14)$. The nurses had been working for 20 years (4-36) since their registration and were of 47 years of age (3859). They had been working at the nurse-led hypertension clinic 1-16 years and 13 of them had special education for working in primary care. The special education on advanced level mirrors what demands are given in primary care and encompasses public health, pedagogy, psychosocial issues, pharmaceutical prescription ability and children's health. This education gives the nurse competence to work of her own, with a physician to consult when needed, at general or specialized clinics at a health center, within children's health care, as a school nurse or in home health care. The nurse at a nurse-led hypertension clinic at a health center has often had special training in hypertension and can see patients for blood pressure measurements and order blood tests prior to visits to the physician, who do the diagnose and prescribe the medication. In between, the nurse manages the patient on her own with visits for follow-up of lifestyle changes or medication. As there are so many hypertensive patients the specialized nurse may take care of the newly diagnosed and/or more complicated patients and the rest of the public health nurses or registered nurses at the health center manage the less demanding hypertensive patients.

The intervention consisting of a residential multifactorial education (Bosworth et al., 2008) lasted for three days. The nurses in the IG were educated in MI (Rollnick, et al., 2002) with patient-centeredness (Table 1) (Drevenhorn et al., 2006), the Stages of Change (SOC) model (Prochaska et al., 1997) and in the application of guidelines for cardiovascular prevention (Mancia et al., 2007), lifestyle factors and pharmacological treatment (Glynn et al., 2010). Video-recorded consultations with simulated patients were included in the training. The recordings were reviewed in small groups with the supervision of the research team (ED, $A B$, KK). No further education was provided during the study period. The results of this counseling training on the communication of nurses with their patients and on patient variables (blood pressure, blood lipids, smoking, taking snuff, weight, waist circumference, body mass index, physical activity, alcohol consumption, perceived stress) have previously been reported (Drevenhorn, et al., 2006; Drevenhorn et al., 2007; Drevenhorn et al., 2009; Drevenhorn et al., 2012). The patient inclusion criteria were hypertensive patients consulting nurses at health centers, men and women aged $<75$ years, systolic blood pressure $\geq 160$ $\mathrm{mmHg}$ and/or diastolic blood pressure $\geq 90 \mathrm{mmHg}$, body mass index $\geq 25 \mathrm{~kg} / \mathrm{m}^{2}$, serum cholesterol $\geq 6.5 \mathrm{mmol} / \mathrm{l}$ and/or serum triglycerides $\geq 2.3 \mathrm{mmol} / \mathrm{l}$, and no reporting of regular physical activity. Nurses in the IG included 153 patients consecutively and in the CG 60 patients were included. Despite the low number of patients included in the CG it was decided to stop the inclusion period after four years after a new power analysis. The number of patients included by each nurse varied from 1 to 14 patients due to different numbers of eligible hypertensive patients at the health centers. During the study period the nurses saw all their patients at the time of inclusion, and after one year and two years, in order to collect data. In addition to that they followed the routines at their respective workplace. Due to the statistical analyses only patients who had complete data collected from all three measurements at baseline, as well as after one and after two years, were included in the final 
analyses, which resulted in 137 patients in the IG and 51 in the CG (Figure 2). The reasons for loss at follow-up were refusal to participate, death, and not meeting inclusion criteria. This has previously been reported in detail (Drevenhorn, et al., 2012). Patients in the CG received the usual care.

The Exercise of Self-Care Agency (ESCA) instrument (Kearney \& Fleischer, 1979) is an instrument measuring the degree to which persons perceive their capability of exercising their self-care agency. The instrument consists of the active versus passive components in being responsible for self-care, motivation to care for oneself, knowledge to apply self-care, and self-worth, which influences self-esteem, and making health priorities. To reflect these components, statements such as "I like myself", "I seek help when unable to care for myself" or "Sometimes when I feel sick, I ignore the feeling and hope it goes away" are used. The instrument has been used in studies on healthy subjects in East Germany (Whetstone, 1987), in the US (Callaghan, 2003), in Japan (Yamashita, 1998) and in Sweden (Whetstone \& Hansson, 1989). The Swedish version (Whetstone \& Hansson, 1989) showed Cronbach’s alpha of 0.78 . Some minor adjustments had to be made by one of the authors (ED) of the questions in the Swedish version to make the language more fluent. There are 43 statements in the instrument with five alternatives to choose between. The alternatives are: A) very characteristic of me, B) somewhat characteristic, C) no opinion, D) somewhat uncharacteristic and E) very uncharacteristic. Alternative A gives 4, B 3, C 2, D 1, and E gives 0 points. This applies for all items except 11 where the statements have a negative meaning and for these items the rating is reversed. The maximum mark is 172 points. The founders of the instrument (Kearney \& Fleischer, 1979) tested it on nursing and psychology students and the score was between about 90 and 154 points with a mean of 122 and 120 respectively.

The nurses in our intervention study achieved patient-centeredness (Table 1) in their counseling to a different degree, as formerly reported (Drevenhorn, et al., 2006). From the analyses of audio recordings with two patients before and after the training, the patientcenteredness was rated from 1 to 3 . A score of 1 meant that at least three parts of patientcenteredness were achieved, 2 meant that at least three parts were achieved but less frequently, and 3 meant that less than three parts of patient-centeredness were achieved. The nurses in the CG did not perform any recordings and therefore patient-centeredness was not rated in this group.

Due to the ordinal character of the analyzed variable, only nonparametric statistical methods were applied. For comparison of ESCA values at baseline, at the 1-year follow-up and at the 2-year follow-up between IG and CG, the Mann-Whitney U-test was used. For comparisons within each group between baseline and follow-up 1 and 2 the Wilcoxon signed rank test was used. The Kruskal-Wallis test was used to analyze differences in ESCA scores between the exercise levels of 1, 2 and 3 with a subsequent application of a Mann-Whitney U-test as a post-hoc analysis. The same procedure was applied for ESCA values regarding the degree of patient-centeredness in the counseling reported earlier (Drevenhorn, et al., 2006). 
The study adheres to the principles outlined in the Declaration of Helsinki and was approved by the Local Ethics Committee at the Faculty of Medicine, University of Gothenburg, Sweden (Ö363-00).

\section{Results}

Demographic data on the patients, where there were no significant differences between the groups, are shown in Table 2. The number of patients who filled in the ESCA instrument completely at baseline and at follow-up at one and two years is shown in Table 3. There was a significant $(\mathrm{p}=0.000)$ difference in the ESCA score from baseline to the two-year follow-up in the IG, while no statistical differences could be seen in the CG. In the IG the women had a significant difference from baseline to the 2-year follow-up ( $\mathrm{p}=0.0001)$, with an increase from 119 to 121.8 and from the 1- to 2-year follow-up with an increase from 117.5 to 121.8 $(\mathrm{p}=0.015)$ points. The men increased their scores from 110 to $112(\mathrm{p}=0.005)$ from baseline to the 2-year follow-up. No statistical differences between the IG and CG were found (Figure 3).

Patients ( $\mathrm{n}=86)$ who were counseled by a nurse who achieved degree 1 in patientcenteredness after the counseling training increased their ESCA score significantly $(p=0.013$ ) from baseline to the follow-up at one year. And for the patients who increased their selfreported physical activity to medium level (biking/walking to workplace $\geq 5 \mathrm{~km} 5$ days/week or vigorous exercise [e.g. gymnastics, ball sports, jogging] twice/week) or high level (vigorous exercise $>$ twice/week) at the 2-year follow-up there was a significant correlation between the increase in ESCA scores both in the IG $(p=0.0001)$ and in the CG $(p=0.040)$. No other associations were found between ESCA scores and patient variables.

\section{Discussion}

This multifactorial tailored education gave a significant increase in self-care agency scores in the IG and also when men and women are considered separately. An increased level of physical activity during the 2-year follow-up was significantly connected with an increase in the score for self-care agency. Furthermore, the higher the patient-centeredness in the counseling sessions in the IG, the higher the score was.

Although the inclusion period was prolonged to four years only 60 patients were found to be included in the CG. The low number of patient is a limitation and the long inclusion period is in itself another limitation as more confounding factors may occur the longer that period lasts. Despite there were no significant demographic differences between the groups we cannot be sure that the difference in level of education was not affecting the results though there were no big differences between the groups regarding white-collar workers and workers.

The aim of the intervention of counseling training for nurses working at hypertension clinics was to increase the nurses' skills in helping patients change their lifestyles as a part of the treatment. We have previously shown successful results from this intervention with regard to greater patient participation (Drevenhorn, et al., 2007), more discussions on the patients' responsibility for their own treatment (Drevenhorn, et al., 2009) and increased negotiations about the reasons for, and where to begin, lifestyle changes (Drevenhorn, et al., 2006) in the 
consultations. These results emphasize the importance of seeing the individual patient and of being aware of different people's ability to understand the value of performing self-care in managing their health problems or disease. The concept of health literacy was further defined by Berkman et al. (2010) ${ }^{(\mathrm{p} 16)}$ as "the degree to which individuals can obtain, process, understand, and communicate about health-related information needed to make informed health decisions.” This concept can be useful for understanding why some people are successful in changing their lifestyle and some are not. The nurses should have this in mind too in order to individualize their counseling. We can assume that the use of MI with its patient-centeredness and the SOC model are valuable tools for treating the very different patients. The men had generally lower scores than the women, and one may wonder why that is. Several studies have found that women in general are more interested in health matters (Franceschi et al., 2000) and this interest is the basis for engagement. This is also confirmed in our data where the men in both groups initially had lower baseline scores (IG 110, CG 106.5) than the women (IG 119, CG 120.5) and did not reach the same score as the women (neither in the IG nor in the CG) even after two years. The impact of patient-centered counseling can be observed by the higher scores of self-care agency in the IG after two years both for the women and the men.

When comparing the median score (IG 117, CG 112) at the 2-year follow-up with results from earlier studies (Kearney \& Fleischer, 1979) in other contexts we can see that American nursing students (122) and psychology students (120) had a higher score. From a population of 17 citizens in East Germany a score of 113,6 was reported (Whetstone, 1987) and 187 citizens in the south of Sweden had a score of 112.5 (Whetstone \& Hansson, 1989). In all of these studies healthy subjects were included, which cannot be compared with our participants, who were diagnosed with hypertension and might find themselves more vulnerable and susceptible than a healthy population. In our study the population consisted of older individuals than was the case in the studies with students and citizens.

Just as we can see how important it is to be patient-centered in counseling patients on lifestyle changes, we can also see that it is very important that we really know that the counseling training is successful. The big challenge is how we can know which kind of education in counseling gives the best patient-centeredness and how we should measure how skillful the individual nurse is in performing patient-centered counseling in daily practice. The MI training is not standardized, although in most courses it lasts for 2-4 days in Sweden. However, this is not sufficient (Mitcheson et al., 2009). The latest research indicates (Forsberg et al., 2010a; Forsberg et al., 2010b) that you have to have supervision during a period of one or two years until you have achieved an acceptable level of patient-centeredness in your counseling. Thereafter you still have to have further training and check yourself with recording consultations and analyze them yourself or have them analyzed by professional coders to maintain your skills. This has to be further studied in order to give the counseled patients a chance to consider their situation and come to a decision as to whether or not to perform a change of lifestyle. 


\section{Conclusions and implications for practice}

The nurses' education in patient-centeredness (MI) and the SOC model gave an increase in self-care agency scores, which was significantly correlated with increased physical activity after two years. In clinical practice it is then important for nurses to be patient centered in their counseling to affect patients' self-care agency in a positive direction.

Table 1. Description of each part of patient-centeredness (Rollnick, et al., 2002).

\begin{tabular}{|c|c|}
\hline Patient-centeredness & Description \\
\hline n questions & $\begin{array}{l}\text { Questions that cannot be answered with just a } \\
\text { "yes" or "no" }\end{array}$ \\
\hline $\begin{array}{l}\text { Using expansive ways } \\
\text { of putting questions }\end{array}$ & $\begin{array}{l}\text { Using questions that start with describe, list, } \\
\text { tell me more, for example, to get the patient to } \\
\text { go into detail and unfold a line of thought }\end{array}$ \\
\hline $\begin{array}{l}\text { Reflecting on what is } \\
\text { said }\end{array}$ & $\begin{array}{l}\text { Repeating the last words, rewording or } \\
\text { checking on something to make sure it has } \\
\text { been correctly understood }\end{array}$ \\
\hline $\begin{array}{l}\text { Perhaps provoking the } \\
\text { patient }\end{array}$ & $\begin{array}{l}\text { Provoking to lead the patient to talk about why } \\
\text { it is necessary to change behavior }\end{array}$ \\
\hline Allowing pauses & $\begin{array}{l}\text { Allowing one's own and the patient's pauses to } \\
\text { leave room for thought and reflection }\end{array}$ \\
\hline $\begin{array}{l}\text { Identifying the patient's } \\
\text { perceived threats to } \\
\text { health }\end{array}$ & $\begin{array}{l}\text { Identifying or actively asking for the patient's } \\
\text { apprehensions of threats to health }\end{array}$ \\
\hline $\begin{array}{l}\text { Identifying the patient's } \\
\text { perceived vulnerability } \\
\text { to complications }\end{array}$ & $\begin{array}{l}\text { Identifying or actively asking for the patient's } \\
\text { apprehensions about complications of } \\
\text { hypertension }\end{array}$ \\
\hline $\begin{array}{l}\text { Making it easier for the } \\
\text { patient to obtain and } \\
\text { assimilate relevant } \\
\text { knowledge }\end{array}$ & $\begin{array}{l}\text { Making it easier to obtain and assimilate } \\
\text { relevant information by giving the patients a } \\
\text { booklet or by checking what they have heard or } \\
\text { read before }\end{array}$ \\
\hline $\begin{array}{l}\text { Helping the patient to } \\
\text { see opportunities of } \\
\text { changing behavior }\end{array}$ & $\begin{array}{l}\text { Giving suggestions about actions to be taken or } \\
\text { giving support for thoughts expressed }\end{array}$ \\
\hline $\begin{array}{l}\text { Helping the patient to } \\
\text { weigh up the pros and } \\
\text { cons for changing } \\
\text { behavior }\end{array}$ & $\begin{array}{l}\text { Asking the patient what he/she appreciates and } \\
\text { what he/she dislikes about a particular behavior }\end{array}$ \\
\hline $\begin{array}{l}\text { Identifying the patient's } \\
\text { beliefs in the power of } \\
\text { changing behavior }\end{array}$ & $\begin{array}{l}\text { Identifying or actively asking for the patient's } \\
\text { beliefs about the efficacy of behavioral change }\end{array}$ \\
\hline
\end{tabular}




\begin{tabular}{|c|c|}
\hline $\begin{array}{l}\text { Negotiating the reason } \\
\text { for behavioral change }\end{array}$ & $\begin{array}{l}\text { Discussing the basis for and the importance of } \\
\text { making changes and the risks of not changing } \\
\text { behavior }\end{array}$ \\
\hline $\begin{array}{l}\text { Negotiating where the } \\
\text { patient should start } \\
\text { his/her behavioral } \\
\text { change }\end{array}$ & $\begin{array}{l}\text { Discussing which behavior to start with and } \\
\text { how the patient could start changing behavior }\end{array}$ \\
\hline $\begin{array}{l}\text { Negotiating the goal for } \\
\text { changing behavior }\end{array}$ & Discussing what the change should produce \\
\hline $\begin{array}{l}\text { Negotiating the } \\
\text { behavior the patient } \\
\text { should change }\end{array}$ & $\begin{array}{l}\text { Discussing the behaviors that are important to } \\
\text { change }\end{array}$ \\
\hline $\begin{array}{l}\text { Summarizing the } \\
\text { counseling }\end{array}$ & Summarizing possible needs for change \\
\hline
\end{tabular}

Table 2. Demographic data on participating patients.

\begin{tabular}{|l|c|c|}
\hline & $\begin{array}{c}\text { Intervention group } \\
\mathrm{n}=137\end{array}$ & $\begin{array}{c}\text { Control group } \\
\mathrm{n}=51\end{array}$ \\
\hline Age, $\mathrm{m}$ & 56.7 & 59.5 \\
\hline Married/lived together, \% & 82.5 & 84.7 \\
\hline Compulsory school, \% & 63.9 & 54.2 \\
\hline Upper secondary school, \% & 20.4 & 33.9 \\
\hline University educated, \% & 15.6 & 1.7 \\
\hline Worker, \% & 62.6 & 62 \\
\hline White-collar worker, \% & 33 & 38 \\
\hline
\end{tabular}


Table 3. Overview of valid answers of the ESCA instrument for the whole group and separately for women and men in IG and CG.

\begin{tabular}{|c|c|c|c|c|c|c|c|c|c|c|c|c|}
\hline \multicolumn{7}{|c|}{ Intervention group $\mathbf{n}=137$} & \multicolumn{6}{|c|}{ Control group $n=51$} \\
\hline & Baseline & 1 year & 2 years & $\mathrm{p} 1$ & $\mathrm{p} 2$ & p3 & Baseline & 1 year & 2 years & $\mathrm{p} 1$ & $\mathrm{p} 2$ & p3 \\
\hline Valid answers n (\%) & $132(96.4)$ & $134(97,8)$ & $132(96,4)$ & & & & 48 (94.1) & 48 (94.1) & $46(90.2)$ & & & \\
\hline Md (range) & $117(70-156)$ & $116(72-159)$ & $117(74-159)$ & 0.013 & 0.005 & 0.000 & $114(71-146.8)$ & $115.8(79-158)$ & $112.6(79-148)$ & 0.910 & 0.360 & 0.570 \\
\hline Men md (range) & $110(65-151)$ & $109(68-115)$ & $112(74-155)$ & 0.063 & 0.110 & 0.005 & $106.5(68-146)$ & $110(74-138)$ & $107.5(79-141)$ & 0.658 & 0.773 & 0.749 \\
\hline Women md (range) & $119(73,7-145)$ & $117.5(67-156)$ & $121.8(79.9-159)$ & 0.103 & 0.015 & 0.000 & $120.5(91-144)$ & $118(89-155)$ & $121(90-148)$ & 0.403 & 0.142 & 0.627 \\
\hline
\end{tabular}

$\mathrm{p} 1=\mathrm{p}$-value baseline -1 year, $\mathrm{p} 2=\mathrm{p}$-value $1-2$ years, $\mathrm{p} 3=\mathrm{p}$-value baseline -2 years 


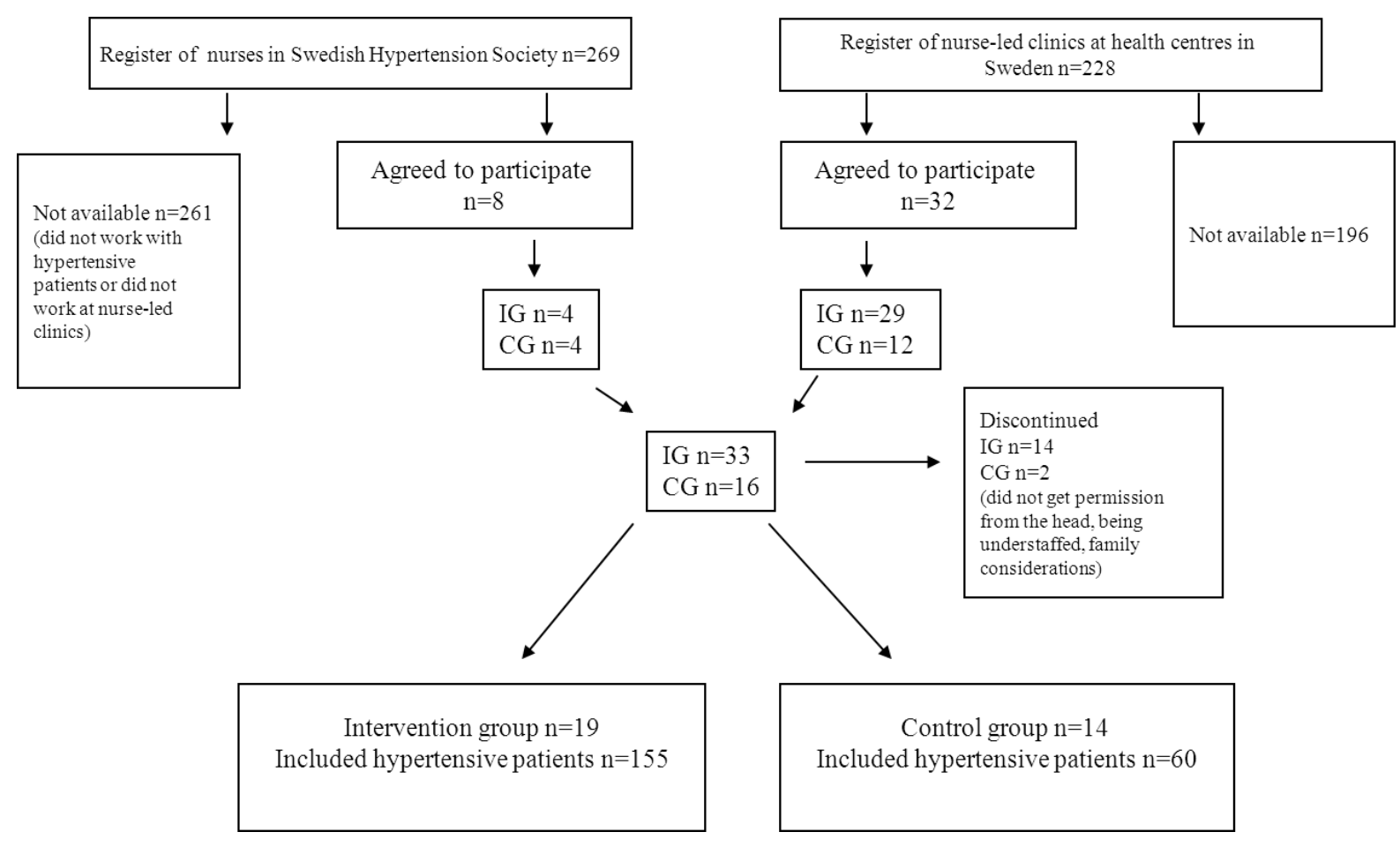

Figure 1. Flow diagram of participating nurses

\section{Intervention group}

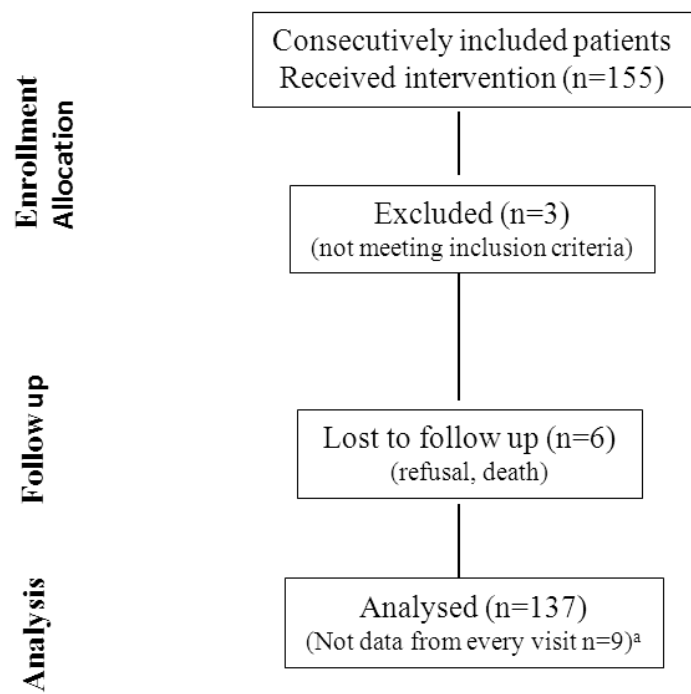

\section{Control group}

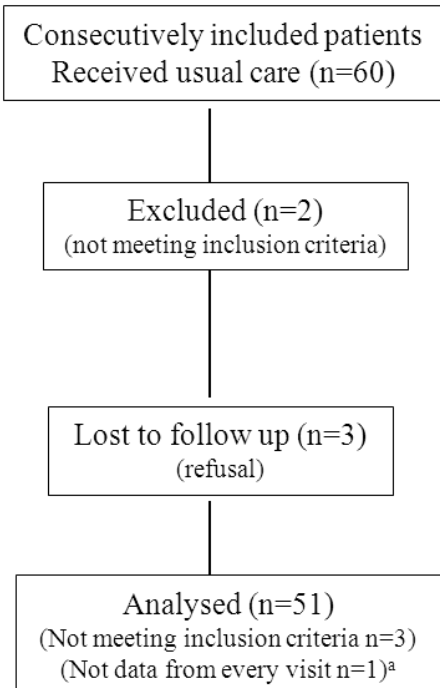

Figure 2. Flow diagram of patients. ${ }^{\text {a }}$ Data missing due to patients not showing up or the nurses being off duty when data should be collected. 


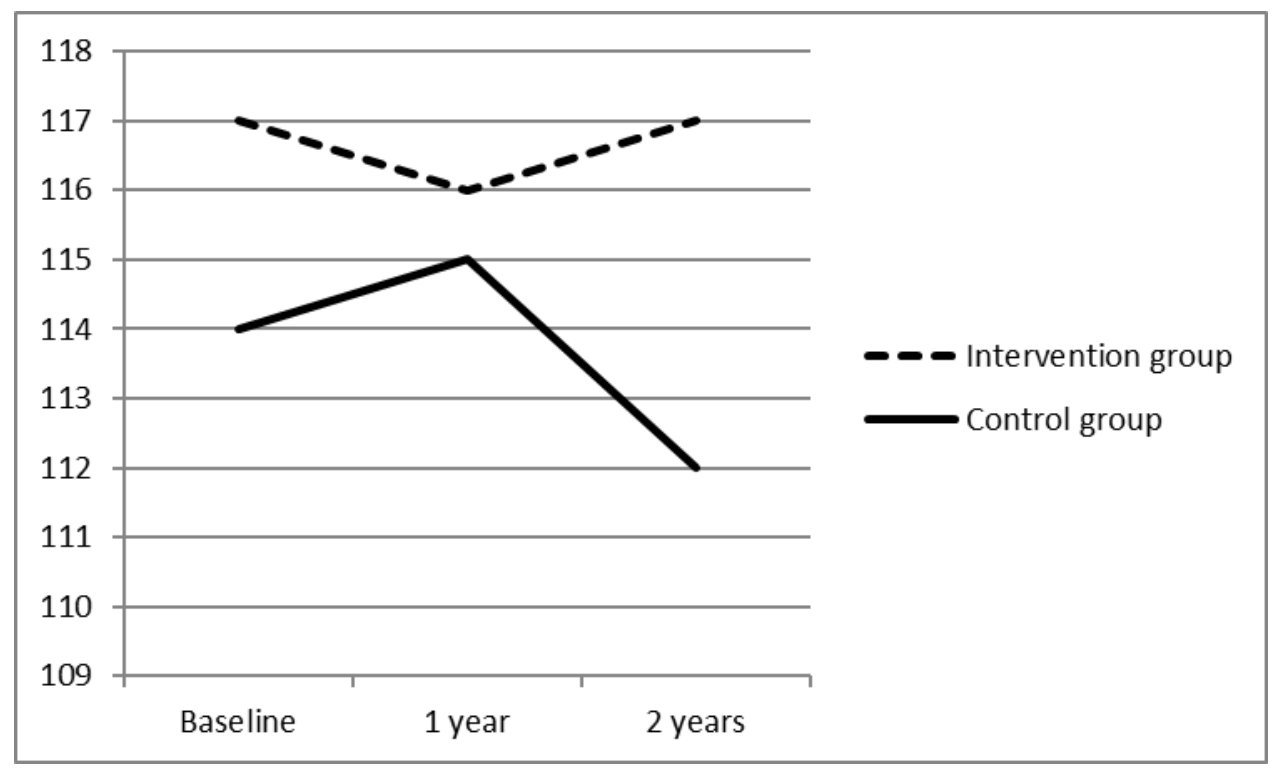

Figure 3. Development of the ESCA scores in the IG and CG from baseline to follow-up after 2 years.

\section{References}

Bengtson, A., \& Drevenhorn, E. (2003). The nurse's role and skills in hypertension care - A review. Clinical Nurse Specialist, 17(5), 260-268.

Berkman, N. D., Davis, T. C., \& McCormack, L. (2010). Health literacy: what is it? Journal of Health Communication, 15 Suppl 2, 9-19. doi: 926926618 [pii] 10.1080/10810730.2010.499985

Bosworth, H. B., Olsen, M. K., Neary, A., Orr, M., Grubber, J., Svetkey, L., . . . Oddone, E. Z. (2008). Take Control of Your Blood Pressure (TCYB) study: a multifactorial tailored behavioral and educational intervention for achieving blood pressure control. Patient Education and Counseling, 70(3), 338-347. doi: S0738-3991(07)00447-8 [pii] 10.1016/j.pec.2007.11.014

Britt, E., Hudson, S. M., \& Blampied, N. M. (2004). Motivational interviewing in health settings: a review. Patient Education and Counseling, 53(2), 147-155.

Callaghan, D. M. (2003). Health-promoting self-care behaviors, self-care self-efficacy, and self-care agency. Nursing Science Quarterly, 16(3), 247-254.

Drevenhorn, E., Bengtson, A., Allen, J. K., Säljö, R., \& Kjellgren, K. I. (2006). A content analysis of patient centredness in hypertension care after consultation training for nurses. The Internet Journal of Advanced Nursing Practice, 8(2).

Drevenhorn, E., Bengtson, A., Allen, J. K., Säljö, R., \& Kjellgren, K. I. (2007). Counselling on lifestyle factors in hypertension care after training on the Stages of Change model. European Journal of Cardiovascular Nursing, 6(1), 46-53.

Drevenhorn, E., Bengtson, A., \& Kjellgren, K. I. (2009). Evaluation of consultation training in hypertension care. European Journal of Cardiovascular Nursing, 8(5), 349-354. doi: S1474-5151(09)00091-7 [pii]10.1016/j.ejcnurse.2009.08.001 
Drevenhorn, E., Bengtson, A., Nilsson, P. M., Nyberg, P., \& Kjellgren, K. I. (2012). Consultation training of nurses for cardiovascular prevention - a randomised study of two years duration. Blood Pressure, 21(5), 293-299.

Forsberg, L., Ernst, D., \& Farbring, C. A. (2010a). Learning motivational interviewing in a real-life setting: a randomised controlled trial in the Swedish Prison Service. Criminal Behavior in Mental Health, 21(3), 177-188. doi: 10.1002/cbm.792

Forsberg, L., Forsberg, L. G., Lindqvist, H., \& Helgason, A. R. (2010b). Clinician acquisition and retention of Motivational Interviewing skills: a two-and-a-half-year exploratory study. Substance Abuse Treatment Prevention Policy, 5, 8. doi: 1747-597X-5-8 [pii]10.1186/1747-597X-5-8

Franceschi, C., Motta, L., Valensin, S., Rapisarda, R., Franzone, A., Berardelli, M., .. . Baggio, G. (2000). Do men and women follow different trajectories to reach extreme longevity? Italian Multicenter Study on Centenarians (IMUSCE). Aging (Milano), 12(2), 77-84.

Fujita, L. Y., \& Dungan, J. (1994). High risk for ineffective management of therapeutic regimen: A protocol study. Rehabilitation Nursing, 19(2), 75-79.

Geden, E. A., Isaramalai, S. A., \& Taylor, S. G. (2001). Self-care deficit nursing theory and the nurse practitioner's practice in primary care settings. Nursing Science Quarterly, 14(1), 29-33.

Glynn, L. G., Murphy, A. W., Smith, S. M., Schroeder, K., \& Fahey, T. (2010). Interventions used to improve control of blood pressure in patients with hypertension. Cochrane Database Syst Rev(3), CD005182. doi: 10.1002/14651858.CD005182.pub4

Jaarsma, T., Abu-Saad, H. H., Dracup, K., \& Halfens, R. (2000). Self-care behaviour of patients with heart failure. Scandinavian Journal of Caring Sciences, 14(2), 112-119.

Jallinoja, P., Pajari, P., \& Absetz, P. (2008). Repertoires of lifestyle change and selfresponsibility among participants in an intervention to prevent type 2 diabetes. Scandinavian Journal of Caring Sciences, 22(3), 455-a462.

Kearney, B. Y., \& Fleischer, B. J. (1979). Development of an instrument to measure exercise of self-care agency. Research in Nursing and Health, 2(1), 25-34.

Mancia, G., De Backer, G., Dominiczak, A., Cifkova, R., Fagard, R., Germano, G., . . . Zanchetti, A. (2007). 2007 ESH-ESC Guidelines for the management of arterial hypertension: the task force for the management of arterial hypertension of the European Society of Hypertension (ESH) and of the European Society of Cardiology (ESC). Blood Pressure, 16(3), 135-232.

Mitcheson, L., Bhavsar, K., \& McCambridge, J. (2009). Randomized trial of training and supervision in motivational interviewing with adolescent drug treatment practitioners. Journal of Substance Abuse Treatment, 37(1), 73-78. doi: S0740-5472(08)00214-6 [pii] 10.1016/j.jsat.2008.11.001

Orem, D. E. (2001). Nursing. Concepts of practice. (6th ed.). St Louis, Missouri: Mosby Year Book Inc.

Pender, N. J. (1996). Health promotion in nursing practice. (3rd ed.). Stamford, Connecticut: Appleton \& Lange. 
Prochaska, J. O., Redding, C. A., \& Evers, K. E. (1997). The transtheoretical model and stages of change. In K. Glanz, F. M. Lewis \& B. K. Rimer (Eds.), Health behavior and health education (2nd ed., pp. 60-84). San Francisco: Jossey-Bass Publishers.

Rollnick, S., Mason, P., \& Butler, C. (2002). Health behavior change: a guide for practitioners. Philadelphia: Churchill Livingstone.

Whetstone, W. R. (1987). Perceptions of self-care in East Germany: a cross-cultural empirical investigation. Journal of Advanced Nursing, 12, 167-176.

Whetstone, W. R., \& Hansson, A.-M. O. (1989). Perceptions of self-care in Sweden: a crosscultural replication. Journal of Advanced Nursing, 14, 962-969.

Whetstone, W. R., \& Reid, J. C. (1991). Health promotion of older adults: perceived barriers. Journal of Advanced Nursing, 16(11), 1343-1349.

Yamashita, M. (1998). The exercise of self-care agency scale. Western Journal of Nursing Research, 20(3), 370-381. 